\title{
Applicability of Willem's Method of Dental Age Assessment in 14 Years Threshold Children in South India - A Pilot Study
}

Ekta Priya*

Department of Pedodontics \& Preventive Dentistry, Asan Memorial Dental College \& Hospital, Kanchipuram District, Tamil Nadu, India

*Corresponding author: Ekta Priya, MDS, DipFHID, Department of Pedodontics \& Preventive Dentistry, Asan Memorial Dental College \& Hospital, Asan Nagar, Keerapakkam, Oragadam Main Road, Kanchipuram District, Tamil Nadu, India, Tel: +919566404435; E-mail: ekta.priya@hotmail.com

Rec date: August 13, 2015 Acc date: September 10, 2015 Pub date: September 16, 2015

Copyright: (c) 2015 Priya E. This is an open-access article distributed under the terms of the Creative Commons Attribution License, which permits unrestricted use, distribution, and reproduction in any medium, provided the original author and source are credited.

\begin{abstract}
Age plays an important role in various fields such as forensic science, various social and legal settings and treatment planning in clinical dentistry. Children with undocumented birth date are vulnerable to violation of various child rights. This pilot study aimed to test the applicability of Willem's method of dental age assessment at the threshold of 14 years considering prohibition of employment of children. The sample consisted of 30 males and 30 females. The dental age estimation was performed by two blinded examiners using Willem's method. The accuracy of Willem's method of age assessment was measured by the difference between the chronological age and estimated dental age. It was seen that there was underestimation of age in both males and females. The difference in females and males were -0.29 years and -0.23 years respectively. The scores of dental maturation described by Willems may be suitable for South Indian children.
\end{abstract}

Keywords: Age estimation; Dental age; Willem's method; South India children; Child labour

\section{Introduction}

The age of a person can be determined by the degree of maturation of the different tissue systems of an individual [1]. Osteogenic and Odontogenic tissues have been successfully used to determine age of individuals with unknown birth records [2,3] Age plays an important role in various fields such as forensic science, various social and legal settings and treatment planning in clinical dentistry [4]. In 2010 UNICEF reported only $41 \%$ of children were registered at birth in India. These children with undocumented birth date are vulnerable to violation of various child rights. One of such violations can be commonly noticed in situations of child labours. As per the National Sample Survey Organization result, the estimated total number of working children was 4.98 million children in the age group of 5-14 in India. Prohibition of employment of children's in factories in constitution of India, Article 24 states that no child below the age 14 years shall be employed in work in any factory or mine or engaged in any other hazardous employment [5-7]. Considering the magnitude of child labour in India, it necessary to identify these vulnerable children and provide the best accurate method of estimating the unknown age.

Estimating age from teeth is considered to be reliable, as maturational events associated with tooth formation are less variable $[8,9]$. Assessment of tooth development to estimate the age of living subjects was first used in 19th century industrial revolution in England. The presence of the first permanent molar was a sign that a child had attained six years of age and such children were condemned to work in the coal mines $[10,11]$. Dental age assessment can be quantified using various methods such as crown root measurements, tooth eruption mouth, and radiographic analysis of stages of tooth formation. A number of studies have been carried out to identify the most appropriate and precise method to estimate dental age [12]. The tooth development stages described by Demirjian et al. is considered the most simple and reliable method as it has the highest values for both intra- and inter-observer agreement [13]. Hence, this method has been widely tested among numerous population groups across the globe [1,14-18].

In 2001, Willems et al. evaluated the accuracy of Demirjian's method in Belgian Caucasian population and modified the scoring system when a significant overestimation was reported [19]. This modified method calculated the overall maturity score by summing the adapted scores for the seven mandibular teeth which presented the result directly as estimated age of the individual. This modification has been evaluated among various population and has been reported to be more accurate than the original Demirjian's method [20-22].

This pilot study aims to test the applicability of Willem's method in South Indian children at the threshold of 14 years of age.

\section{Materials and Methods}

The panoramic radiographs were obtained from the Department of Oral and Maxillofacial Radiology, Saveetha Dental College \& Hospital. The data consisted of 30 panoramic radiographs of boys and 30 panoramic radiographs of girls aged between 13-15 years. The panoramic radiographs had been taken previously for routine diagnostic purpose from the period between August 2014 to November 2014.

\section{Selection criteria}

- Children without any known developmental, endocrinal or nutritional disorders affecting growth

- Children between 13 to 15 years of age

- The presence of all the seven left or right mandibular permanent teeth present (erupted or not)

- Children of South Indian descendants from parents of same ethnicity 


\section{Chronological age}

Chronological age was recorded as decimal years using the date of birth mentioned by the parents and the date on which the panoramic radiographs was taken.

\section{Dental age assessment by Willem's method}

Tooth development is divided into eight stages (A-H) as proposed by Demirjian and co-workers and score for each developmental stage of each tooth were obtained by the score chart given by Willem's et al. The sum of score for the seven teeth provided the estimated dental age of the individual. All the seven mandibular teeth on the left side were included in the scoring process. When a tooth on the left side was missing, the corresponding tooth on the right side was substituted and scored.

The scoring was done by two blinded examiners.

\section{Difference between the chronological age and estimated dental age}

The accuracy of Willem's method of age assessment was measured by the difference between the chronological age and estimated dental age estimated. A positive result indicates an overestimation and negative figure an underestimation of age.

Statistical analysis was done using SPSS Version 17.0 for Windows (SPSS Inc, Chicago, IL). The mean and standard deviation of chronological age and estimated dental age were calculated for males and females in each group categorized according to the age of the subject. The mean difference between chronological age and dental age was also calculated.

For evaluating inter-examiner reproducibility, 10 panoramic radiographs were randomly selected from the radiographs used in this study and re-scored after a period of at least 2 weeks by the two blinded examiners and the Cohen Kappa values were calculated.

\section{Results}

This study consisted of 30 females and 30 males. Table 1 demonstrates frequency and percentage distribution of males and females subjects. For the 30 females the mean chronological age was 13.79 years and standard deviation 0.72 . For the 30 males subjects the mean chronological age was 13.85 years and standard deviation 0.89 .

\begin{tabular}{|c|c|c|c|c|c|c|}
\hline \multirow{3}{*}{ Year of Birth } & \multicolumn{4}{|c|}{ Gender } & \multicolumn{2}{|c|}{ Total } \\
\hline & \multicolumn{2}{|c|}{ Boys } & \multicolumn{2}{|c|}{ Girls } & \multirow[b]{2}{*}{$\mathbf{N}$} & \multirow[b]{2}{*}{$\%$} \\
\hline & $\mathbf{N}$ & $\%$ & $\mathbf{N}$ & $\%$ & & \\
\hline 1998 & 8 & 26.7 & 10 & 33.3 & 18 & 30 \\
\hline 1999 & 13 & 43.3 & 8 & 26.7 & 21 & 35 \\
\hline 2000 & 9 & 30 & 12 & 40 & 21 & 35 \\
\hline Total & 30 & 100 & 30 & 100 & 60 & 100 \\
\hline
\end{tabular}

Table 1: Distribution of study subjects according to year of birth.

Table 2 demonstrates the comparison between chronological age and dental age with respect to the mean difference and standard deviation. The inter-rater agreement Kappa score for the tooth development stages was calculated to be 0.87 . This demonstrated almost perfect agreement for this method of assessment.

\begin{tabular}{|c|c|c|c|c|c|c|}
\hline \multirow{3}{*}{ Gender } & \multirow{2}{*}{\multicolumn{2}{|c|}{ Chronological Age (CA) }} & \multirow{3}{*}{$\begin{array}{l}\text { Gender } \\
\text { Mean }\end{array}$} & \multirow{2}{*}{\multicolumn{2}{|c|}{$\begin{array}{l}\text { Dental } \\
\text { Age (DA) }\end{array}$}} & \multirow{3}{*}{$\begin{array}{l}\text { Mean difference } \\
\text { (CA-DA) }\end{array}$} \\
\hline & & & & & & \\
\hline & Mean & Standard Deviation & & $\begin{array}{l}\text { Standard } \\
\text { Deviation }\end{array}$ & & \\
\hline Boys & 13.79 & 0.722 & Boys & 14.02 & 1.572 & $0.23 \pm 0.85$ \\
\hline Girls & 13.85 & 0.892 & Girls & 14.14 & 1.46 & $0.20 \pm 0.57$ \\
\hline Total & 13.82 & 0.805 & Total & 14.08 & 1.506 & $0.26 \pm 0.7$ \\
\hline
\end{tabular}

Table 2: Mean comparison between chronological age and dental age of the study subjects.

Estimated dental age assessment by Willem's method appeared to underestimate chronological age both in males and females. However, the difference was greater in females when compared to males. The difference in females and males were 0.29 years and 0.23 years respectively. Subsequently, the required sample size with power of 80 and $\alpha$ error set at 0.05 was calculated to be 200 .

\section{Discussion}

Considering the legal and social importance of 14 years of age with respect to employment and child labour in India, this pilot study aimed to test the accuracy of Willem's method in children of South Indian origin. The dental age estimation method employed should estimate the age of the individual as close to the chronological age as possible and remain consistent and reliable over repeated measurements. 
Willem's method is based on the stages of the tooth development described by Demirjian and co-workers. Ozle et al. in 2005 reviewed the various methods of staging and found that the Demirjian classification achieved the highest values for both observer agreement and for correlation between the stages as defined by the method and true age. Therefore, Ozle et al. regarded Demirjian's system to be the best for dental age estimation [23]. However, modified Demirjian's method proposed by Willem's has been tested in various geographic population groups and has shown higher accuracy than Demirjian's method dental age estimation [20,24]. The accuracy of Willem's method can be contributed to its single step calculation from the gender specific chart. Another reason could be the influence of secular trend. Jayaraman et al. reported that there a difference in dental maturity between children born in 1980 and 2000. Hence, children born two decades later exhibited secular trend [25].

The estimated by Willem's method was compared with the "gold standard" chronological age. The difference was reported as the mean age difference. Mean difference is considered to be more appropriate measure of accuracy than other measure accuracy including correlation coefficient because it allows understanding the difference between the chronological age and estimated dental age in units, i.e., in decimal years [13].

A recent study by RB Mohammed et al., conducted among South Indian children who concluded that mean dental age showed significant underestimation of $0.7 \pm 1.69$ years and $0.11 \pm 1.3$ years in boys and girls respectively [26]. However a study conducted among North Indian population by Grover et al. reported that the method overestimated age of girls and boys by 0.24 and 0.36 years respectively [20].

Unlike the results of this pilot study, a study conducted in Iran concluded that Willem's method overestimated the age by 0.30 years in girls and 0.42 years in boys [27]. Similarly, Galić et al. noted Willem's method to overestimate the age by 0.24 and 0.42 years, in girls and boys respectively [28].

In their systematic review and meta-analysis on applicability of Demirjian's method of age assessment on various global population, Jayaraman et al. in 2013, reported and posed that Demirjian's method of age estimation overestimates the age of the subjects by more than 6 months [13]. This pilot study reported an underestimation of age by a mean difference of $-0.26(\mathrm{SD}=1.32)$ corresponding to around 4 months for total sample and thus the author suggests Willem's method being comparatively accurate method could be used to assess the age of employed children in age dispute questions.

Sample size is one of the important criterions for generalizing the results obtained by the applicability of any dental age estimation method to a specific population. Studies conducted using a smaller sample size cannot infer the accuracy of dental age estimation method to a population as a whole. Another concern regarding sample size arises when applicability of dental age estimation becomes gender specific. Hence, an extensive and adequate sample is needed to justify the accuracy of the dental age estimation method to a specific population. The sample size of the subjects calculated by this pilot study was 200. Considering the various statistical analysis, sample characteristics and applicability of dental age estimation methods, the author recommends formulation of universal protocol or guidelines for conducting such population based studies.

\section{Conclusion}

This pilot study reported comparatively high accuracy of Willem's method at 14 years threshold. The scores of dental maturation described by Willems in 2000 is suitable for South Indian children. However, this preliminary study would be extended for further validation of this method in larger sample in the tested population. Future research work is warranted for testing of this method with other important age threshold.

\section{Acknowledgement}

The author would like to thank the Department of Oral Medicine and Radiology, Saveetha Dental College for providing the panoramic radiographs. The author would also like to thank Dr. G. Deepa, Department of Pedodontics and Preventive Dentistry, Saveetha Dental College \& Hospital and Dr. Jayakumar Jayaraman, Founder and Director of Date of Birth Foundation for their guidance.

\section{References}

1. Hegde RJ, Sood PB (2002) Dental maturity as an indicator of chronological age: radiographic evaluation of dental age in 6 to 13 years children of Belgaum using Demirjian methods. J Indian Soc Pedod Prev Dent 20: 132-138.

2. Jayaraman J, King NM, Roberts GJ, Wong HM (2011) Dental age assessment: are Demirjian's standards appropriate for southern Chinese children? J Forensic Odontostomatol 29: 22-28.

3. Yadava M, Roberts GJ, Lucas VS (2011) Dental age assessment (DAA): reference data for British children at the 10-year-old threshold. Int J Legal Med 125: 651-657.

4. Koshy S, Tandon S (1998) Dental age assessment: the applicability of Demirjian's method in south Indian children. Forensic Sci Int 94: 73-85.

5. Child Protection \& Child Rights, Vulnerable Children, Children's Issues, Birth Registration.

6. Central Government Act. Article 24 in the Constitution of India 1949

7. Size and distribution of child labor in India and Punjab.

8. Maia MC, Martins Mda G, Germano FA, Brandão Neto J, da Silva CA (2010) Demirjian's system for estimating the dental age of northeastern Brazilian children. Forensic Sci Int 200: 177.

9. Chertkow S, Fatti P (1979) The relationship between tooth mineralization and early radiographic evidence of the ulnar sesamoid. Angle Orthod 49: 282-288.

10. Roberts GJ, Parekh S, Petrie A, Lucas VS (2008) Dental age assessment (DAA): a simple method for children and emerging adults. Bri Dent J 204: 192-193.

11. Saunders E (1837) The Teeth a Test of Age, considered with Reference to the Factory Children. The British and the foreign medical review 8: 76.

12. Peiris TS, Roberts GJ, Prabhu N (2009) Dental Age Assessment: a comparison of 4- to 24-year-olds in the United Kingdom and an Australian population. Int J Paediatr Dent 19: 367-376.

13. Jayaraman J, Wong HM, King NM, Roberts GJ (2013) The FrenchCanadian data set of Demirjian for dental age estimation: a systematic review and meta-analysis. J Forensic Leg Med 20: 373-381.

14. Eid RM, Simi R, Friggi MN, Fisberg M (2002) Assessment of dental maturity of Brazilian children aged 6 to 14 years using Demirjian's method. Int J Paediatr Dent 12: 423-428.

15. Mani SA, Naing L, John J, Samsudin AR (2008) Comparison of two methods of dental age estimation in 7-15-year-old Malays. Int J Paediatr Dent 18: 380-388.

16. Nykänen R, Espeland L, Kvaal SI, Krogstad O (1998) Validity of the Demirjian method for dental age estimation when applied to Norwegian children. Acta Odontol Scand 56: 238-244. 
Citation: Priya E (2015) Applicability of Willem's Method of Dental Age Assessment in 14 Years Threshold Children in South India - A Pilot Study. J Forensic Res S4: S4-002. doi:10.4172/2157-7145.1000S4-002

Page 4 of 4

17. Tunc ES, Koyuturk AE (2008) Dental age assessment using Demirjian's method on northern Turkish children. Forensic Sci Int 175: 23-26.

18. Jayaraman J, Roberts GJ, King NM, Wong HM (2012) Dental age assessment of southern Chinese using the United Kingdom Caucasian reference dataset. Forensic Sci Int 216: 68-72.

19. Willems G, Van Olmen A, Spiessens B, Carels C (2001) Dental age estimation in Belgian children: Demirjian's technique revisited. J Forensic Sci 46: 893-895.

20. Grover S, Marya CM, Avinash J, Pruthi N (2012) Estimation of dental age and its comparison with chronological age: accuracy of two radiographic methods. Med Sci Law 52: 32-35.

21. Nik-Hussein NN, Kee KM, Gan P (2011) Validity of Demirjian and Willems methods for dental age estimation for Malaysian children aged 5-15 years old. Forensic Sci Int 204: 208.

22. Djukic K, Zelic K, Milenkovic P, Nedeljkovic N, Djuric M (2013) Dental age assessment validity of radiographic methods on Serbian children population. Forensic Sci Int 231: 398.

23. Olze A, Bilang D, Schmidt S, Wernecke KD, Geserick G, et al. (2005) Validation of common classification systems for assessing the mineralization of third molars. Int J Legal Med 119: 22-26.
24. Ramanan N, Thevissen P, Fleuws S, Willems G (2012) Dental age estimation in Japanese individuals combining permanent teeth and third molars. J Forensic Odontostomatol 30: 34-39.

25. Jayaraman J, Wong HM, King N, Roberts G (2013) Secular trends in the maturation of permanent teeth in 5 to 6 years old children. Am J Hum Biol 25: 329-334.

26. Mohammed RB, Sanghvi P, Perumalla KK, Srinivasaraju D, Srinivas J, et al. (2015) Accuracy of four dental age estimation methods in southern Indian children. J Clin Diagn Res 9: HC01-08.

27. Javadinejad S, Sekhavati H, Ghafari R (2015) A Comparison of the Accuracy of Four Age Estimation Methods Based on Panoramic Radiography of Developing Teeth. J Dent Res Dent Clin Dent Prospects 9: $72-78$.

28. Galić I, Vodanović M, Cameriere R, Nakaš E, Galić E, et al. (2011) Accuracy of Cameriere, Haavikko, and Willems radiographic methods on age estimation on Bosnian-Herzegovian children age groups 6-13. Int J Legal Med 125: 315-321. 